\title{
Tax simplification: The April 2006 changes to UK pensions taxation
}

Received: 11th August, 2005

\section{John Coulthard}

is a senior consultant with Hewitt Associates in London. He read mathematics at Oxford University and became a Fellow of the Institute of Actuaries in 2002. John holds a number of Scheme Actuary appointments to large private sector pension schemes in the UK. Since the government published its blue-print in 2002, John has provided advice to clients on the implications of the April 2006 tax changes. John has also helped with Hewitt's overall policy for addressing these changes.

\section{Tony Baily}

is a principal consultant with Hewitt Associates. He provides strategic and prototype consulting ideas to companies and pension scheme trustees on a full range of pensions and benefits issues. These include valuations and financing, benefit design and communication, sales and acquisitions, scheme restructuring and changes from government reform. His personal clients include major UK and multinational organisations. Tony regularly speaks at conferences and seminars on pensions issues. He is a Fellow of the Institute of Actuaries and has a first-class mathematics degree from Warwick University.

John Coulthard

Hewitt Bacon \& Woodrow 6 More London Place London, ES1 2DA, UK.

Tel: $+44(0) 2079394312$ Fax: $+44(0) 1372757507$ e-mail:

john.coulthard@hewitt.com

\begin{abstract}
In April 2006, the UK Government will radically simplify its taxation of pensions vehicles. This paper sets out the key changes, and reports on how the market is responding in the short term. The paper also considers the wider impact of the new legislation on pensions savings.

Keywords: Lifetime Allowance; Annual Allowance; Primary Protection; Enhanced Protection; Earnings Cap; UURBS; FURBS
\end{abstract}

\section{The arrival of 'A'-Day - April 2006}

This paper sets out the implications of the landmark pensions taxation changes in the UK, which apply from April 2006. The paper is structured as follows:

1 Overview of the current tax regime.

2 What is changing - the new tax regime.

3 How the market has reacted for high earners.

4 The wider implications for UK pensions savings.

As these issues are discussed, there is a basic subdivision into two categories:

- Short-term changes, such as executive reward strategy — where the market has had to react urgently, and where the implications are generally now clear.

- Long-term changes, such as flexible retirement - where it is possible to speculate on the implications, but where the end-state is largely unknown.

\section{Overview of the current tax regime}

The UK currently has eight separate taxation regimes for pensions. The applicable tax regime varies according to when an individual joined a pensions arrangement, and on the type of that arrangement (eg an insurance contract or a vehicle set up by a private sector company). 
The current approach leads to bewildering complexity for savers, and has arisen partly due to 'grandfathering' - whereby protection was given to existing savers whenever the government made a policy change. This has led to many layers of categories and special cases.

The current tax regimes are rooted to the concept of applying limits to the level of permitted pensions savings. Either the inputs to a pensions vehicle (ie contributions) are limited, and/or the outputs (ie benefits) are limited. Often these limits are difficult to calculate, leading to significant compliance costs.

For readers unfamiliar with how approved UK pensions vehicles are taxed, here is an overview of the three stages:

- Tax treatment of input: Contributions to the pensions vehicle are tax-exempt.

- Tax treatment of assets of pensions vehicle: Investment returns on accumulated contributions are broadly tax-exempt.

- Tax treatment of output: Benefit payments fall into two categories for taxation purposes:

- Annuity (or 'pension') payments are subject to income tax, which is currently 40 per cent for high-earners.

- Cash lump sums are not subject to tax. The amount of benefit that can be taken in this format is strictly limited.

This is sometimes described as an 'Exempt, Exempt, Taxed' regime.

\section{What's changing - The new tax regime}

This section introduces the Lifetime Allowance and the Annual Allowance, explains how existing benefits can be protected, and looks at the decisions that need to be revisited on the 'Earnings Cap' (which arose from the Finance Act 1989).

\section{Lifetime Allowance}

In a bold and welcome move, the Finance Act 2004 sweeps away the multitude of existing tax regimes with effect from April 2006, and replaces them with a simple single regime.

At the heart of the new regime is the so-called 'Lifetime Allowance'. This defines how much pension can be built up in a tax-efficient way. It starts at $£ 1.5 \mathrm{~m}$ in April 2006 and moves up to f $1.8 \mathrm{~m}$ over the following five years. Its progression after that will be announced every five years.

People are free to build up pensions savings that exceed the Lifetime

Allowance. However, this will lead to an additional tax charge of 25 per cent. There is some grandfathering of existing benefits, which will provide some protection for existing savers, and which has been organised in a way that is easily compatible with the Lifetime Allowance. This is explained further in the section 'Transitional protection'.

The Lifetime Allowance is applied as follows:

- For defined contribution vehicles, such as personal pensions, the amount of the individual's pot is compared with the Lifetime Allowance at retirement to check whether the allowance has been exceeded.

- For defined benefit vehicles, such as final salary schemes, the amount of pension is converted to a 'value' using a conversion factor of $£ 20$ for each E1 per annum of accrued pension, and then this value is compared with the Lifetime Allowance. Note: The 
position is a little more complicated for valuing pensions in payment, or for valuing benefits with high pension increases.

The following example illustrates how the Lifetime Allowance test is carried out.

\section{Example data}

- Individual has a deferred pension of $£ 50,000$ each year from a defined benefit scheme.

- Individual has an accumulated 'pot' of f.1m from a defined contribution scheme.

- The Lifetime Allowance is $£ 1.5 \mathrm{~m}$ at point of retirement.

- The member has not selected any transitional protection (see next section).

\section{Step 1: Calculate 'value' of benefits}

- Value of defined benefit pension $=20 \times £ 50,000=£ 1 \mathrm{~m}$, using the Revenue's prescribed methodology.

- Value of defined contribution pot $=$ f,1m

- Total value of pension benefits $=f_{1} 1 \mathrm{~m}+f_{1} 1 \mathrm{~m}=\delta^{2} \mathrm{~m}$

Step 2: Check value of benefits against Lifetime Allowance

Here, the value of benefits exceeds the Lifetime Allowance by $f^{2} \mathrm{~m}-1.5 \mathrm{~m}=$ f $^{0.5 \mathrm{~m}}$.

\section{Step 3: Calculate amount of additional tax}

The benefit in excess of the Lifetime Allowance (valued at $60.5 \mathrm{~m}$ in this example) can be taken as pension or cash, and the tax charge is similar in both cases.

\section{Pension}

The value of the excess pension is subject to an additional tax charge of 25 per cent which is payable up front. The remaining excess pension payments are then subject to income tax.

This gives a total tax of around $(25 \%+40 \% \times 75 \%)=55$ per cent on the excess benefit; which compares with tax of 40 per cent on benefits within the Lifetime Allowance.

\section{Cash}

If the individual takes the 'excess benefit' in the form of a cash lump sum, then the cash is subject to an immediate tax charge of 55 per cent.

Note: Although the tax payable is broadly similar under the pension and cash routes, it is not necessarily identical. For example, the total amount of tax payable under the pension option (which includes income tax on the pension payments) depends on how long the individual lives.

\section{Annual Allowance}

The Lifetime Allowance is the new philosophy which says that individuals can save as much as they like in a pensions vehicle, but only a certain amount can be done in the most tax-efficient way.

The Finance Act 2004 also establishes the 'Annual Allowance'. This is an annual limiter on how quickly savers can increase their benefits in a tax-efficient way. The Annual Allowance starts at $£_{215,000}$ and increases to $\mathcal{E}^{255,000}$ over five years, subject to a maximum of 100 per cent of the individual's taxable earnings over the year.

People are free to build up their pensions savings more quickly than by the Annual Allowance. However, tax is payable on the excess (currently 40 per cent for high earnings), and this is in addition to the tax that will apply once the benefits come into payment. Savers will want to avoid this double taxation, 
as it will make pensions savings very inefficient - and some companies have already put policies in place to mitigate this possibility.

The Annual Allowance is applied as follows:

- For defined contribution vehicles, the amount of contributions paid over the tax year are checked against the Annual Allowance.

- For defined benefit vehicles, the amount of additional pension accrued over the year is multiplied by 10 and tested. For example, if an individual's accrued pension increased from $, 50,000$ per annum to $\mathcal{6} 65,000$ per annum over the year, then the increase (ie $\mathcal{E} 15,000$ per annum) would be multiplied by 10 (giving $\mathcal{K} 150,000)$ and compared with the Annual Allowance $\left(\mathcal{K}^{215,000)}\right.$.

Notes:

- The Annual Allowance is broadly 1/7th of the Lifetime Allowance.

- In the year before retirement, the Annual Allowance test does not apply. This helps schemes to continue to provide early retirement enhancements, eg for members retiring as a result of serious ill-health.

\section{Transitional protection}

The government recognises that some individuals (particular those who joined pensions arrangements before the introduction of the Earnings Cap in 1989) will already have built up significant benefits. Furthermore, they did so in the good faith that the fiscal system supported these benefits.

The Revenue has therefore created two levels of grandfathering of benefits, called Primary Protection and Enhanced Protection. Individuals can choose one or both of these options.

\section{Primary Protection}

The first level of protection is aimed at individuals with benefits over the $£ 1.5 \mathrm{~m}$ Lifetime Allowance at 6th April, 2006. Under Primary Protection, these individuals can 'bank' the value of their benefits at that date (eg $\left.f^{2} \mathrm{~m}\right)$, by registering for a Personal Lifetime Allowance.

The Personal Lifetime Allowance (eg $\left.f^{2} \mathrm{~m}\right)$ grows at the same rate as the standard Lifetime Allowance (so if the standard Lifetime Allowance increased from $\mathcal{E} 1.5 \mathrm{~m}$ to $\mathcal{E} 1.8 \mathrm{~m}$, an individual's Personal Lifetime Allowance would

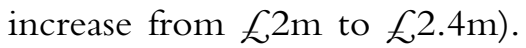

Under Primary Protection, individuals can continue to earn benefits. However, the value of any benefits at retirement in excess of the Personal Lifetime

Allowance at retirement is subject to the additional tax charge. (So if benefits are valued at $\mathcal{E}^{2.7 \mathrm{~m}}$ and the Personal Lifetime Allowance is $f^{2} .4 \mathrm{~m}$, then additional tax is payable on the excess of f0.3m).

Primary Protection is only available for individuals with benefits in excess of the Lifetime Allowance of $£ 1.5 \mathrm{~m}$ at 6 th April (and it would be pointless to try to protect an amount smaller than the standard Lifetime Allowance).

\section{Enhanced Protection}

There is a second level of protection, which guarantees that no extra taxation will be paid on benefits earned before 6th April, 2006.

There is a serious price to pay for this enhanced level of protection individuals who choose this option are not allowed to earn pensions benefits above those accrued at 6th April, 2006, by which the Revenue means:

- For defined benefit members, benefits earned at 6th April, 2006 can increase in line with the greater of RPI, 5 per 
cent per annum or salary increases (if they are salary linked). If benefits increase by more than this, then the Enhanced Protection is cancelled by the Revenue, and members may face a hefty tax bill.

- For defined contribution members, benefits can increase in line with investment returns; here, Enhanced Protection is revoked if additional contributions are made after April 2006.

Individuals who choose Enhanced Protection will expect their employer to provide an alternative benefit as a substitute for future pension accrual, eg cash (otherwise the individual would be better off earning extra pension and paying tax on this).

Enhanced Protection may be considered by individuals with benefits that are worth less than $\mathcal{N}^{1.5 \mathrm{~m}}$ at 6th April, 2006, eg if they are concerned that investment returns alone will take them above the Lifetime Allowance.

\section{The Earnings Cap, UURBS and FURBS}

The Finance Act 1989 is famous in the UK for introducing the 'Earnings Cap'. The Earnings Cap is a ceiling of around $\mathcal{E} 100,000$ that restricts the amount of earnings on which pensionable benefits can be provided. It applies only to individuals who joined a pensions arrangement after 1st June, 1989.

The UK marketplace has developed a number of solutions to deal with this fiscal constraint, the most popular of which are known as Unfunded Unapproved Retirement Benefit Schemes (UURBS) and Funded Unapproved Retirement Benefit Schemes (FURBS). These vehicles deliver benefits that look like regular pensions benefits, but through a fiscal framework that is less tax-efficient than applies to approved pensions vehicles.
An UURBS is simply a written promise that a company will provide benefits to an individual - usually to top up an existing approved scheme benefit to the level that would have been payable had the cap not been introduced. Normally no funds are built up to provide security for these benefits (though a reserve must be built up on the balance sheet for such benefits, so the shareholders know the extent of these unfunded promises).

A FURBS is similar to an UURBS, with the distinguishing feature being that funds are set aside (through a legal trust) to provide security for the benefits. A FURBS therefore looks like the majority of funded UK pensions arrangements; however, there are differences in the way these benefits are taxed. The key difference is that individuals are taxed on the contributions paid into a FURBS and are able to take the whole benefit as a tax free lump sum at retirement (this is sometimes known as a 'Taxed, Taxed, Exempt' regime).

The following are general comments on how the new tax regime will impact on these vehicles; however, please note that unapproved pensions vehicles are an area where specialist advice is almost certainly required:

- UURBS: These vehicles broadly retain their existing features, provided that no more than 25 per cent of benefits are paid out as cash (with the remainder paid as pension). All benefits continue to be taxed as income in payment. Experience suggests existing UURBS are continuing for most organisations that already have these vehicles.

- FURBS: The tax treatment of these vehicles has worsened. They are now generally being closed to future accrual, and are sometimes being wound up completely. For future benefits, some organisations are setting 
up UURBS in place of FURBS. The loss of security for individuals in doing this has led to increased interest in 'secured UURBS', which are UURBS with some security being provided by the sponsoring company (eg in the form of a fixed or floating charge).

Note: For individuals subject to the Earnings Cap, the maximum benefit under the current regime is a pension of two-thirds of the cap. This has a 'value' of approximately $\mathcal{K}^{1.5 \mathrm{~m}}$ at April 2006, using the Revenue's conversion factor of 20. It is no coincidence that this is the opening amount of the Lifetime

Allowance and, more generally, the Lifetime Allowance can be considered as an evolutionary advance on the Earnings Cap. The Lifetime Allowance is much simpler to apply than its predecessor (reducing compliance costs), and the 'allowance' philosophy is more flexible.

\section{How the market has reacted for high earners}

As with any change to a taxation system, much of the initial work is focused on the boundary points - here, the existing Earnings Cap and the new $£ 1.5 \mathrm{~m}$ Lifetime Allowance. Many companies have already reviewed their reward strategy in respect of these issues.

\section{Earnings Cap}

For members who joined a pension scheme after 1989, their benefits are currently restricted by the Earnings Cap. From April 2006, schemes can remove the Earnings Cap.

Experience has identified the following market reactions:

- Most schemes are keeping a cap in place for past service benefits so that individuals do not receive a windfall gain, and because many of these individuals have already received alternative compensation.

- Where an organisation does not provide an explicit alternative benefit for earnings above the Earnings Cap, the cap is usually being kept in place for future service as well as for past service.

- Organisations that already provide an explicit alternative benefit (eg a FURBS) for capped members are often removing the Earnings Cap for future service benefits, in place of the alternative benefit.

\section{New £1.5m Lifetime Allowance}

Transitional protection is available for individuals at Primary and Enhanced levels.

Experience has identified the following market reactions:

- Nearly all companies are being proactive in identifying who may be affected.

- Individuals who are considering Enhanced Protection are expecting their employer to provide an alternative benefit to future pension accrual. The majority of leading companies are providing an alternative.

- The most popular alternative to pensions benefits is additional cash, which is sometimes calculated to have the same expected cost as the pensions benefit it is replacing, but is often a more general rate (eg 20 per cent of salary). Some companies are only offering selected members this option. At the other end of the spectrum, some other companies are integrating pensions into their 'flex' programmes and are giving every employee the choice of cash rather than pension, not just those impacted by the Lifetime Allowance. 
- Where organisations have UURBS vehicles already, these are continuing after April 2006 in most cases as an alternative to future approved pensions accrual. Some organisations are giving individuals the chance to transfer their UURB benefit into their approved pensions vehicle (this can be tax-efficient if their benefits are well within the Lifetime Allowance).

- Most companies are briefing executives on their options, eg through one-to-one surgeries. Some companies are offering access to independent financial advice.

Little advance information is available on what forms of protection individuals will choose.

It is believed that some individuals will prefer to bust the Lifetime Allowance and pay additional tax, rather than choose Enhanced Protection.

Although the additional tax charge on exceeding the Lifetime Allowance may appear penal, this is not necessarily the case, especially for younger individuals. Pensions vehicles are tax-efficient compared with many savings vehicles because investment returns (both before and after retirement) are broadly free of tax. This tax-free roll-up of investment returns will mitigate the extra tax on exceeding the Lifetime Allowance.

\section{Silver bullet solutions}

In the initial aftermath of the announcement of the Lifetime Allowance, there was a lot of excitement about potential 'silver bullet' solutions for executive reward. Except for the simple solutions of cash, UURBS (where these vehicles have been established already) and 'flex', no viable alternatives to pensions vehicles have really taken off.

The lack of progress here has stemmed partly from the UK Government's determination to clamp down on tax avoidance vehicles - with new ideas needing Revenue approval before they can be implemented.

In addition, companies have been reluctant to use share-based vehicles as alternatives, as they are often perceived as being a fundamentally different type of remuneration to pensions benefits (share-based remuneration is often structured to be performance-related, while pensions are predominantly nonperformance-related).

\section{The wider implications for UK pensions savings}

The Finance Act 2004 introduces a host of other changes which require decisions from schemes and which require action from the scheme administrators and/or changes to software platforms. In particular:

- Schemes can increase the amount of benefits that can be taken as tax-free cash for many members.

- Death benefits can now be made more tax-efficient, eg by paying cash rather than annuity payments for a death in service benefit.

- As part of the Finance Act 2004 changes, it will now be possible to work for an employer and to draw a pension from that employer simultaneously. This is an exciting change, and paves the way for individuals to gradually phase from working to retirement (eg by initially moving to a three-day week while drawing half of their pension).

These points are developed further in Mike Hammer's article 'Pensions tax simplification: The impact on scheme design' (Pensions, Vol. 10, No. 4, pp. 295-302).

In addition, there are significant 
implications for schemes with overseas aspects (such as schemes based outside of the UK which provide benefits to individuals with UK contracts of employment). The overseas aspects of the changes are not addressed in this brief paper.

Addressing the Finance Act 2004 changes has led to a short-term burst of extra compliance costs for companies and savers, although these may be recouped over time as the benefits of the simpler regime become apparent.

The long-term impact of the changes is likely to be greater simplicity and transparency for pensions vehicles, and greater choice for individuals.

It is believed that pensions will continue to be a popular savings vehicle, as a result of their significant fiscal advantages compared with other savings products.

The popularity of UK pensions vehicles may also be increased by the new flexibility on funding. Previously, pension contributions were limited to broadly 15 per cent of earnings (a higher amount applies for personal pensions and similar vehicles), but now individuals can pay up to 100 per cent of earnings (or the Annual Allowance, if lower). This makes it easier for individuals to put in money when it suits them best, depending on their own financial circumstances that will vary over their working lifetime.

\section{Closing remarks}

The taxation of pensions in the UK will change radically from April 2006. The new regime is simpler, and offers more flexibility for savers.

The key intellectual change is that the concept of applying limits to the inputs/outputs of pensions vehicles has been replaced with the more flexible concept of applying allowances. Individuals can exceed the allowances, but there are tax implications of doing so. It will be interesting to see whether this new thinking is adopted in other fiscal regimes around the world.

The changes have led to a significant short-term focus on the existing Earnings Cap and the new Lifetime Allowance.

The Earnings Cap was the previous landmark change to UK pensions taxation, and applies to individuals who joined their scheme after 1989. Decisions are needed by schemes on whether to keep this restriction in place for past and/or future benefits. Decisions are also needed on what to do with any pensions vehicles that were set up as a result of the Earnings Cap (eg UURBS and FURBS).

The Lifetime Allowance will apply to all individuals who have UK pensions benefits, and retrospectively replaces all tax regimes that came before it.

However, members of schemes at April 2006 can choose two levels of protection for their existing rights, called Primary Protection and Enhanced Protection.

The Enhanced Protection is only available if individuals severely curtail their pensions accrual after April 2006, and is generally only likely to be attractive to individuals if their employer offers them an alternative form of benefit in place of future pensions accrual. Experience suggests the most popular market solutions here are to offer cash, UURBS and/or flex.

\section{Acknowledgments}

The authors thank their colleagues Andrew Kieran, Colin Mayes and Finn Clawson for their help with this paper. 